\title{
Evaluation of Access to Care for Patients with Chronic Kidney Disease Not on Dialysis in Saint-Louis Region (SENEGAL)
}

\author{
Seck Sidy Mohamed1,2*, Doupa Dominique ${ }^{2,3}$, Ndongo Modou1, Ahoui Seraphin4, \\ Diop-Dia Amadou', Dia Diatou Gueye ${ }^{1}$, Ngouampa Blaise Magloire', Enguerran Macia²
}

\author{
${ }^{1}$ Internal Medicine and Nephrology Department, University Gaston Berger, Saint-Louis, Senegal \\ ${ }^{2}$ UMI 3189 Environnement, santé, sociétés (CNRS/Université Cheikh Anta Diop/Université de Bamako/CNRST Burkina-Faso), \\ Faculté de Médecine, de Pharmacie et d'Odontostomatologie, Dakar, Senegal \\ ${ }^{3}$ Biochemistry Department, University Gaston Berger, Saint-Louis, Senegal \\ ${ }^{4}$ Nephrology Department, Borgou Regional Teaching Hospital, Parakou, Benin \\ Email: *sidymseck@gmail.com
}

How to cite this paper: Mohamed, S.S., Dominique, D., Modou, N., Seraphin, A., Amadou, D.-D., Gueye, D.D., Magloire, N.B. and Macia, E. (2020) Evaluation of Access to Care for Patients with Chronic Kidney Disease Not on Dialysis in Saint-Louis Region (SENEGAL). Open Journal of Nephrology, 10, 1-10.

https://doi.org/10.4236/ojneph.2020.101001

Received: December 3, 2019

Accepted: January 28, 2020

Published: January 31,2020

Copyright $\odot 2020$ by author(s) and Scientific Research Publishing Inc. This work is licensed under the Creative Commons Attribution International License (CC BY 4.0).

http://creativecommons.org/licenses/by/4.0/

\begin{abstract}
Introduction: Patients with chronic diseases, especially kidney diseases, frequently use the health care system and free dialysis policies are being implemented in many countries in Africa. This study aimed to evaluate access to care for patients with chronic kidney disease (CKD) in northern region of Saint-Louis. Methodology: In a cross-sectional survey, we included non-dialyzed CKD patients aged $\geq 20$ years who attended outpatient nephrology clinic at University Hospital of Saint-Louis between January $1^{\text {st }}$ and January $31^{\text {st }} 2018$. Access to care was measured using a questionnaire that integrated dimensions such as availability, geographic and financial accessibility, convenience, acceptability, effectiveness of care and quality of information. Socio-demographic and clinical data were also collected and analyzed with Epi Info 7. Results: Among 97 surveyed patients, 90 were included (response rate of $92.8 \%)$. Patients' mean age was 35.2 years (20 - 89 years) and $55 \%$ were male. Only $30 \%$ of patients had health coverage either by the government, or private insurance or community health insurance. Access to care was rated as globally low by $73 \%$ of participants. However, we noticed some variations according to dimensions of access. Geographical accessibility and convenience of delivered care were good for the majority of patients, while financial access and acceptability of care were considered as very limited. Bivariate analysis showed that acceptability and effectiveness of care were linked to CKD stage while the quality of patients' information was correlated with their educational level. Furthermore, health coverage was also associated with financial accessibility of care but not with its availability. Conclusion:
\end{abstract}


This study showed that access to care is poor for majority of patients with CKD in Saint-Louis. Identification of the main barriers will help define appropriate strategies to achieve universal access to quality renal care.

\section{Keywords}

Access to Care, Chronic Kidney Disease, Saint-Louis

\section{Introduction}

Chronic kidney disease (CKD) represents a challenging health issue that affects around $10 \%$ of the global population [1]. Like in other chronic diseases, patients with CKD need to frequently use health care services with subsequently high psychosocial and treatment costs [2]. This often limits patients' access to care such as renal replacement therapy and contributes to increased mortality from CKD [3] [4]. Access to care can be defined simply as the ability of patients to use health services promptly to have the best possible response to their health problems [5]. This definition is far from consensual because it is simplistic and does not encompass all dimensions of this complex concept of access to care. Over the past decade, WHO kept recommending to policymakers at national and international levels to better address populations' low access to care to achieve universal health coverage [6]. This goal means that all people have access to the health services they need, and at the time they need it and at affordable prices. However, various strategies are used from one country to another to achieve universal health coverage. Thus, in sub-Saharan Africa, many countries implemented very quickly generous decisions by making treatment of some medical conditions free of charge for vulnerable patients [7]. In Senegal, good from head lobbying of health professionals and associations pushed the government to firstly subsidize up to $80 \%$ of dialysis cost before making it completely free of charge for all patients in public facilities since 2012 [8]. This resulted in a rapid increase in demand for dialysis care, while supply has remained very limited despite efforts to build new centers and train qualified personnel in the country's outlying regions. As a result, a large proportion of patients with renal insufficiency who still have difficulty accessing treatment persist. This situation is mainly due to the lack of a proper assessment of the needs, demand, and supply of nephrology care, which should be the prerequisite for any policy decision to improve patient care. Given the absence of studies on this topic in Senegal and sub-Saharan Africa in general, we proposed to assess the level of access to care for patients with chronic kidney disease in the Saint-Louis region (Northern Senegal).

However, as a prelude to these proactive strategies, an objective assessment of access to care is rarely carried out. This study aims to evaluate access to care for patients with chronic kidney disease (CKD) who are not yet on dialysis in the Saint-Louis region. 


\section{Patients and Methods}

In a cross-sectional qualitative survey at the outpatient nephrology clinic in Regional University Hospital of Saint-Louis between January 1st and January 31st, 2018, we assessed the perception of access to care among patients. During this period, we selected all patients aged $\geq 20$ years who attended the clinic with a diagnosis of CKD not yet in dialysis (estimated glomerular filtration rate between 90 and $15 \mathrm{ml} / \mathrm{min} / 1.73 \mathrm{~m}^{2}$ ).

Access to care was measured using a questionnaire based on Penchasky-Thomas's model (see Figure 1) [9] which included the following dimensions:

- availability: the presence of the required staff and resources for care;

- geographical access: the patient's ability to reach a healthcare provider not so far from his living area;

- financial access: patient's ability to afford the cost of care;

- convenience: the extent to which a patient feels comfortable with the delivered care;

- acceptability: the extent to which the care system respects the patient's culture, values, and privacy;

- efficacy of care: the extent to which the delivered care satisfied patient's health demand;

- quality of information: the patient's knowledge of the availability and the procedures to access the care.

In addition to these dimensions of health access, we collected socio-demographical (age, gender, marital status, living area, income level, education level, health coverage) and clinical data and co-morbidities.

Statistical analysis was conducted using Epi Info 7 software. The results are expressed as mean $+/-$ standard deviation or percentages depending on the type of variable. Spearman and Pearson's correlation coefficients were used to identify factors associated with access to care. For all statistical tests, a probability $p \leq$ 0.05 was considered as significant.

\section{Results}

A total of 97 patients were surveyed and 90 of them accepted to be included (92.8\% response rate). The mean age of patients was 35.2 years (extremes 20 - 89 years) and the sex ratio was 1.22. More than three-quarters of patients already used traditional medicines as their first treatment. Income level was low to moderate for $77.5 \%$ of patients and only $41.4 \%$ had health coverage (see Table 1 ). The main comorbidities associated with CKD were high blood pressure (63\%) and diabetes (50\%).

Overall access to care was rated as low according to $73.3 \%$ of patients with CKD. No difference was noticed between males and females regarding access to care. However, there was a high variability according to the dimension of access considered. Figure 2 presents the patients' ratings of various dimensions of 


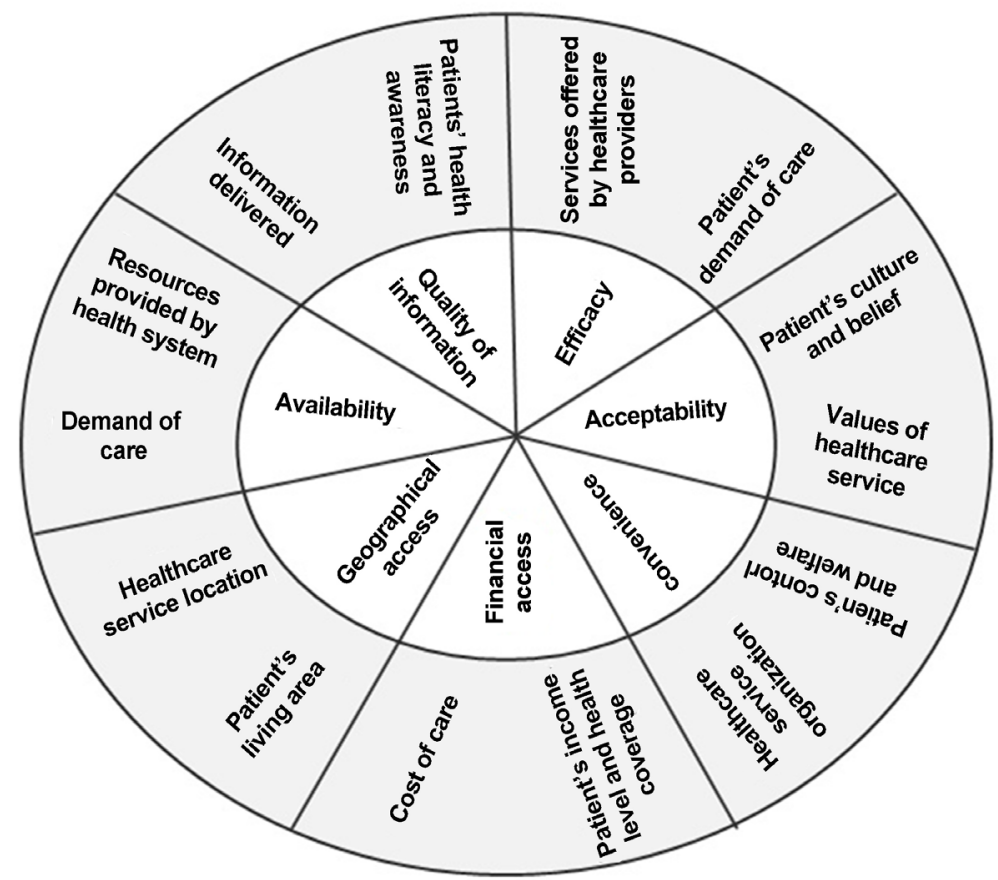

Figure 1. Theoretical framework of access to care (adapted from Penchasky-Thomas's model).

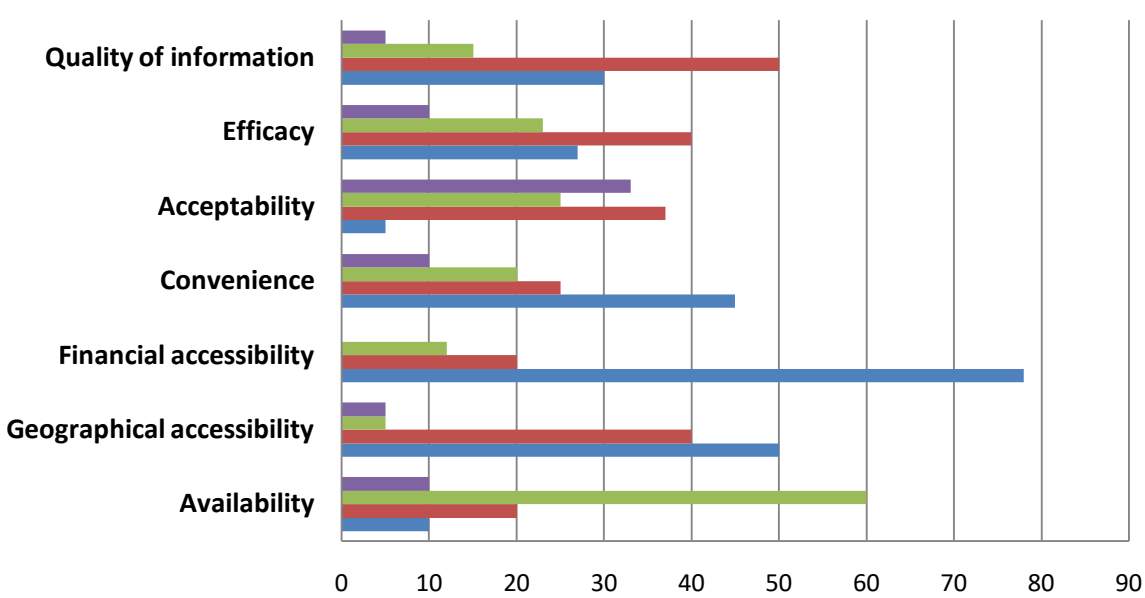

\begin{tabular}{|c|c|c|c|c|c|c|c|}
\hline & \multirow[b]{2}{*}{ Availability } & \multirow{2}{*}{$\begin{array}{c}\text { Geographica } \\
\text { I } \\
\text { accessibility }\end{array}$} & \multicolumn{3}{|c|}{ Patients' rating sclae } & \multirow[b]{2}{*}{ Efficacy } & \multirow[b]{2}{*}{$\begin{array}{c}\text { Quality of } \\
\text { information }\end{array}$} \\
\hline & & & $\begin{array}{c}\text { Financial } \\
\text { accessibility }\end{array}$ & Convenience & Acceptability & & \\
\hline Excellent & 10 & 5 & & 10 & 33 & 10 & 5 \\
\hline Good & 60 & 5 & 12 & 20 & 25 & 23 & 15 \\
\hline$\square$ Fair & 20 & 40 & 20 & 25 & 37 & 40 & 50 \\
\hline Poor & 10 & 50 & 78 & 45 & 5 & 27 & 30 \\
\hline
\end{tabular}

Figure 2. Level of access to care in patients with chronic kidney disease.

patient access to care. Geographic accessibility and acceptability were satisfactory for most of the patients while financial accessibility and convenience were rated very low. Bivariate analysis showed the main factors correlated with different dimensions of access to care in our patients (Table 2). 
Table 1. Socio-demographical and clinical characteristics of patients $(n=90)$.

\begin{tabular}{|c|c|c|c|}
\hline Variables & $\begin{array}{l}\text { Mean } \pm \text { SD } \\
\text { (extremes) }\end{array}$ & Number of patients & Frequency (\%) \\
\hline Age (years) & $\begin{array}{c}35.2 \pm 19.6 \\
(20-89)\end{array}$ & & \\
\hline \multicolumn{4}{|l|}{ Gender } \\
\hline Male & & 50 & $55.5 \%$ \\
\hline Female & & 40 & $45.5 \%$ \\
\hline \multicolumn{4}{|l|}{ Education level } \\
\hline No literacy & & 47 & $52.2 \%$ \\
\hline Primary school & & 20 & $22.2 \%$ \\
\hline Secondary school & & 17 & $18.9 \%$ \\
\hline University & & 06 & $06.7 \%$ \\
\hline \multicolumn{4}{|l|}{ Marital status } \\
\hline Married & & 40 & $(45.5 \%)$ \\
\hline Single & & 38 & $(42.2 \%)$ \\
\hline Widow & & 12 & $(13.3 \%)$ \\
\hline \multicolumn{4}{|l|}{ Income level } \\
\hline Low & & 51 & $56.7 \%$ \\
\hline Moderate & & 19 & $21.1 \%$ \\
\hline High & & 20 & $22.2 \%$ \\
\hline \multicolumn{4}{|l|}{ Living area } \\
\hline Urban & & 67 & $74.4 \%$ \\
\hline Rural & & 23 & $25.6 \%$ \\
\hline \multicolumn{4}{|l|}{ Health coverage status } \\
\hline No health coverage & & 53 & $58.9 \%$ \\
\hline Government insurance & & 21 & $23.3 \%$ \\
\hline Community-based insurance & & 10 & $11.1 \%$ \\
\hline Private insurance & & 06 & $06.7 \%$ \\
\hline \multicolumn{4}{|l|}{ Stage of chronic kidney disease } \\
\hline CKD stage $1-2$ & & 08 & $08.9 \%$ \\
\hline CKD stage $3 a-3 b$ & & 19 & $21.1 \%$ \\
\hline CKD stage $4-5$ & & 63 & $70.0 \%$ \\
\hline \multicolumn{4}{|l|}{ Associated chronic diseases } \\
\hline Hypertension & & 57 & $63.3 \%$ \\
\hline Diabetes & & 44 & $48.9 \%$ \\
\hline Overweight/Obesity & & 51 & $56.7 \%$ \\
\hline
\end{tabular}

Acceptability and efficacy of care were correlated with the CKD stage while the quality of information was associated with patients' educational level. As expected, income level was strongly correlated with financial accessibility. The convenience of delivered care was better rated among men compared to women. Furthermore, health coverage was directly correlated with financial accessibility 
Table 2. Variables associated with dimensions of access to care.

\begin{tabular}{|c|c|c|c|c|c|c|c|}
\hline \multirow[t]{2}{*}{ Variables } & \multicolumn{7}{|c|}{ Dimensions of access to care } \\
\hline & Availability & $\begin{array}{l}\text { Geographical } \\
\text { access }\end{array}$ & Financial access & Convenience & Acceptability & Efficacy & Quality of information \\
\hline \multirow{2}{*}{ Age $>40$ ans } & $\mathrm{r}=0.08$ & $\mathrm{r}=0.53$ & $\mathrm{r}=0.59$ & $\mathrm{r}=0.25$ & $\mathrm{r}=0.63$ & $\mathrm{r}=0.01$ & $\mathrm{r}=0.10$ \\
\hline & $\mathrm{p}=0.30$ & $\mathrm{p}=0.21$ & $\mathrm{p}=0.44$ & $\mathrm{p}=0.13$ & $\mathrm{p}=0.75$ & $\mathrm{p}=0.64$ & $\mathrm{p}=0.09$ \\
\hline \multirow{2}{*}{ Gender } & $\mathrm{r}=0.02$ & $\mathrm{r}=0.24$ & $\mathrm{r}=0.04$ & $\mathrm{r}=-0.12$ & $\mathrm{r}=0.46$ & $\mathrm{r}=0.03$ & $\mathrm{r}=0.02$ \\
\hline & $\mathrm{p}=0.23$ & $\mathrm{p}=0.86$ & $\mathrm{p}=0.20$ & $\mathrm{p}=0.08$ & $\mathrm{p}=0.77$ & $\mathrm{p}=0.14$ & $\mathrm{p}=0.37$ \\
\hline \multirow{2}{*}{ Income level } & $\mathrm{r}=0.41$ & $\mathrm{r}=0.53$ & $\mathrm{r}=0.86$ & $\mathrm{r}=0.01$ & $\mathrm{r}=0.50$ & $r=-0.05$ & $\mathrm{r}=0.23$ \\
\hline & $\mathrm{p}=0.62$ & $\mathrm{p}=0.47$ & $\mathrm{p}=0.02$ & $\mathrm{p}=0.33$ & $\mathrm{p}=0.61$ & $\mathrm{p}=0.27$ & $\mathrm{p}=0.11$ \\
\hline \multirow{2}{*}{ Living area } & $\mathrm{r}=0.32$ & $\mathrm{r}=-0.21$ & $\mathrm{r}=0.27$ & $\mathrm{r}=0.40$ & $r=-0.35$ & $\mathrm{r}=0.06$ & $\mathrm{r}=0.04$ \\
\hline & $\mathrm{p}=0.03^{*}$ & $\mathrm{p}=0.48$ & $\mathrm{p}=0.05^{\star}$ & $\mathrm{p}=0.73$ & $\mathrm{p}=0.22$ & $\mathrm{p}=0.54$ & $\mathrm{p}=0.29$ \\
\hline \multirow{2}{*}{ Education level } & $\mathrm{r}=0.15$ & $\mathrm{r}=0.30$ & $\mathrm{r}=-0.01$ & $\mathrm{r}=0.03$ & $\mathrm{r}=0.11$ & $\mathrm{r}=0.07$ & $\mathrm{r}=0.35$ \\
\hline & $\mathrm{p}=0.23$ & $\mathrm{p}=0.51$ & $\mathrm{p}=0.79$ & $\mathrm{p}=0.44$ & $\mathrm{p}=0.04^{\star}$ & $\mathrm{p}=0.40$ & $\mathrm{p}=0.02^{\star}$ \\
\hline \multirow{2}{*}{ Health coverage } & $\mathrm{r}=0.13$ & $\mathrm{r}=-0.15$ & $\mathrm{r}=0.38$ & $\mathrm{r}=0.37$ & $\mathrm{r}=0.21$ & $\mathrm{r}=0.52$ & $\mathrm{r}=0.05$ \\
\hline & $\mathrm{p}=0.40$ & $\mathrm{p}=0.10$ & $\mathrm{p}=0.02^{\star}$ & $\mathrm{p}=0.25$ & $\mathrm{p}=0.90$ & $\mathrm{p}=0.20$ & $\mathrm{p}=0.64$ \\
\hline \multirow{2}{*}{ CKD stage } & $\mathrm{r}=0.53$ & $\mathrm{r}=0.24$ & $\mathrm{r}=0.01$ & $\mathrm{r}=-0.12$ & $\mathrm{r}=-0.23$ & $\mathrm{r}=0.31$ & $r=0.26$ \\
\hline & $\mathrm{p}=0.44$ & $\mathrm{p}=0.68$ & $\mathrm{p}=0.13$ & $\mathrm{p}=0.40$ & $\mathrm{p}=0.05^{\star}$ & $\mathrm{p}=0.04^{*}$ & $\mathrm{p}=0.10$ \\
\hline \multirow{2}{*}{ Hypertension } & $r=0.35$ & $\mathrm{r}=0.04$ & $\mathrm{r}=0.79$ & $r=0.26$ & $\mathrm{r}=0.51$ & $\mathrm{r}=0.33$ & $r=0.03$ \\
\hline & $\mathrm{p}=0.91$ & $\mathrm{p}=0.66$ & $\mathrm{p}=0.47$ & $\mathrm{p}=0.30$ & $\mathrm{p}=0.28$ & $\mathrm{p}=0.12$ & $\mathrm{p}=0.74$ \\
\hline \multirow{2}{*}{ Diabetes } & $\mathrm{r}=0.87$ & $\mathrm{r}=0.45$ & $\mathrm{r}=0.28$ & $r=-0.56$ & $\mathrm{r}=0.17$ & $\mathrm{r}=0.05$ & $\mathrm{r}=-0.10$ \\
\hline & $\mathrm{p}=0.16$ & $\mathrm{p}=0.23$ & $\mathrm{p}=0.45$ & $\mathrm{p}=0.70$ & $\mathrm{p}=0.64$ & $\mathrm{p}=0.32$ & $\mathrm{p}=0.88$ \\
\hline
\end{tabular}

${ }^{*}$ Correlation statistically significant $(p \leq 0.05)$.

of care but this was not true with availability. Neither age nor gender had any influence on access to care in our patients across all CKD stages.

\section{Discussion}

Access to care for patients with CKD is very poorly studied. The few reported data in nephrology focused on dialysis population and they demonstrated that the most disadvantaged patients had poorer access to care and a much higher risk of progression to end-stage renal disease while they also tended to start dialysis later [2]. Given its complexity and multidimensional nature, the notion of access to care is often difficult to capture in a single study. In this study, we tried to go beyond the classical conception of access (geographical and financial accessibility) which were the most studied in public health and included other dimensions such as acceptability, convenience, and quality of information. This approach presents the advantage to unveil many other issues that could hamper the overall perception of access to care for patients.

Barriers to adequate access to care for patients with chronic diseases can be identified at several levels in the health system. At the strategic level, health policies at the national and international levels often lead to biased planning and distribution of resources (human and material) and care services that lead to significant imbalances in favor of certain populations, areas or acute infectious diseases considered as public health priorities [10]. That's why investments to improve the availability and quality of nephrology care are very low in many African countries. At the operational level, administrative burdens in the patient circuit and direct out-of-pocket payment systems for care are added to the mal 
governance of healthcare structures where the majority of services offered to patients do not take into account their socio-cultural context, believes or even their therapeutic choices [9] [11]. For instance, more than two-thirds of our patients were not satisfied with the convenience of care and one third found that they provided care was not consistent with their culture and beliefs. This aspect is often ignored or superficially addressed by medical practitioners, but it can be an important factor in building patient loyalty to the health care system. On the other hand, so-called "traditional" medicine gives a central place to the patient's conviction and his socio-cultural environment.

Another barrier to access to care is the poor quality of communication between the patient and his healthcare provider. Less than $20 \%$ of patients in our study were satisfied with the information given by the physician about their condition. Low education levels probably contributed to this misperception in medical information and the acceptability of care. Good communication depends not only on the attitude of healthcare professionals and their ability to communicate but also on patients' level of health education and "literacy" [12]. Previous studies have shown that individuals with low levels of health background (also called literacy) are less receptive to health promotion and prevention activities and are less able to self-manage their chronic disease such as CKD [13].

The issue of poor access to care in patients with chronic diseases is not specific to developing countries since even in developed countries there are growing inequalities between population groups according to age, race, socio-economic level or civic status [14] [15]. A survey in adults participating in an early detection and follow-up program for chronic kidney disease showed that the lack of health insurance, non-Caucasian origin, and presence of co-morbidities [16]. In the same study, the authors found that elderly patients had better access to nephrology care compared with younger patients at all stages of CKD [16]. Conversely, age was not correlated with any of the dimensions of access among our patients. Only income level was associated with financial access to care while living area (rural/urban) was significantly correlated with the availability of care for patients with CKD. Studies among African American patients with CKD showed other barriers to access such as low trust in healthcare providers, stress and social discrimination [17].

In addition to the availability of skilled human resources and adequate material, continuity of care and optimal control of CKD progression factors are essential parameters for improving access and quality of renal care [18].

In order to achieve fair access to effective, affordable and sustainable care for patients with NCDs, multidisciplinary and concerted actions should be taken across all components of the health system. Empowering primary health care services with guidelines could be a cost-effective strategy [19]. Indeed, even if a direct link between access to primary health care and the demand for care for patients with chronic diseases is still controversial [20], it seems logical that guaranteeing a minimum package of basic healthcare services, including preventive 
activities, could have a significant impact on the demand and use of specialized care, particularly patients with kidney diseases. In this study, the absence of renal care in primary health care facilities in the whole region of Saint-Louis contributed probably to the difficulty to have access to a kidney specialist. Like in majority of developing countries, Senegalese healthcare system is underfinanced and having many hospitals with specialist doctors are not available out of big capital cities. Nevertheless, despite financial resources shortage, there is a strong political will to develop various types of universal medical insurance coverage in some African countries such as Senegal, Ghana, Gabon, Cote d'Ivoire, Kenya, and Benin, and to reduce health access inequalities [21].

However, several lines of evidence demonstrated that the best strategies for improving access to care are those which integrate patient demand and health services supply [11] [19]. Our results showed that the existence of a health coverage system was positively correlated with financial accessibility but not with the availability of care. This is probably due to the scarce number of health facilities offering nephrology care in the northern part of Senegal. The university hospital in Saint-Louis is the only health facility with a nephrology department and dialysis unit. Better management of patients with CKD could be achieved through information and sensitization of populations and the creation of strong national health insurance systems that can cover the cost of care. Empowering patients will also help to have a better quality of information and more convenient personalized care.

The use of new digital technologies could help to reduce geographical and financial barriers to access to care, especially for people living in remote areas or those with low-income levels. Recently, some tele-nephrology experiments conducted in the USA demonstrated better control patients' blood pressure and a slower progression of their renal disease [22].

\section{Limitations of the Study}

Our study has several limitations related first to the cross-sectional design and the small sample size that does not allow generalization of these preliminary results to the whole population with CKD. Also, we used a qualitative tool to measure access to care but it was very useful to better explore this multidimensional concept, which could not be captured by a single quantitative variable.

Also, our survey focused on patients' perceptions of access to care but did not take into account the views of other actors in the health system such as healthcare providers and health system managers.

\section{Conclusion}

This qualitative study showed that on several dimensions, access to care is not yet satisfactory for patients with CKD living in northern Senegal. Patient satisfaction can be related not only to classical dimensions such as geographic and financial accessibility but also to the convenience, acceptability, and efficacy of 
care. A direct consequence of poor access to care is a delay in the diagnosis and treatment of the disease, which can lead to complications or catastrophic health expenditures, particularly in vulnerable populations. The identification of the main barriers can help to define appropriate strategies to reach universal access to quality care. For that, we need better integration of chronic disease management into primary health care and rational use of digital technology can also help to improve patients 'access to care.

\section{Conflicts of Interest}

The authors declare no conflicts of interest regarding the publication of this paper.

\section{References}

[1] Stanifer, J.W., Jing, B., Tolan, S., et al. (2014) The Epidemiology of Chronic Kidney Disease in Sub-Saharan Africa: A Systematic Review and Meta-Analysis. The Lancet Global Health, 2, e174-e118. https://doi.org/10.1016/S2214-109X(14)70002-6

[2] Lyanage, T., Ninomiya, T., Jha, V., et al. (2015) Worldwide Access to Treatment for End-Stage Renal Disease: A Systematic Review. The Lancet, 385, 1975-1982. https://doi.org/10.1016/S0140-6736(14)61601-9

[3] White, S., Chadban, S., Jan, S., Chapman, J.R. and Cass, A. (2008) How Can We Achieve Global Equity in Provision of Renal Replacement Therapy? Bulletin of the World Health Organization, 86, 229-237. https://doi.org/10.2471/BLT.07.041715

[4] Couser, W., Remuzzi, G., Mendis, S. and Tonelli, M. (2011) The Contribution of Chronic Kidney Disease to the Global Burden of Major Non-Communicable Diseases. Kidney International, 80, 1258-1270. https://doi.org/10.1038/ki.2011.368

[5] World Health Organization (2010) Health System Financing: The Path towards Universal Coverage. WHO, Geneva.

[6] Vega, J. (2013) Universal Health Coverage: The Post-2015 Development Agenda. The Lancet, 381, 179-180. https://doi.org/10.1016/S0140-6736(13)60062-8

[7] Émilie, R. and Samb, O.M. (2012) For a Mapping of Free Health Care in West Africa. Contemporary Africa, 243, 100-101.

[8] Law No. 2012-18 of 17 December 2012 on the Finance Law for the Year 2013. Official Journal of the Republic of Senegal. http://www.jo.gouv.sn/spip.php?article9739

[9] Penchansky, R. and Thomas, J.W. (1981) The Concept of Access: Definition and Relationship to Consumer Satisfaction. Medical Care, 19, 127-140.

https://doi.org/10.1097/00005650-198102000-00001

[10] Marshall, S.J. (2004) Developing Countries Face Double Burden of Diseases. Bulletin of the World Health Organization, 82, 255.

[11] McLaughlin, C.G. and Wyszewianski, L. (2002) Access to Care: Remembering Old Lessons. Health Services Research, 37, 1441-1443. https://doi.org/10.1111/1475-6773.12171

[12] Nutbeam, D. (2008) The Evolving Concept of Health Literacy. Social Science \& Medicine, 67, 2072-2078. https://doi.org/10.1016/j.socscimed.2008.09.050

[13] Berkman, N.D., Sheridan, S.L., Donahue, K.E., et al. (2011) Low Health Literacy and Health Outcomes: An Updated Systematic Review. Annals of Internal Medicine, 155, 97-107. https://doi.org/10.7326/0003-4819-155-2-201107190-00005 
[14] Agabiti, N., Pirani, M., Schifano, P., et al. (2009) Income Level and Chronic Ambulatory Care Sensitive Conditions in Adults: A Multicity Population-Based Study in Italy. BMC Public Health, 9, 457. https://doi.org/10.1186/1471-2458-9-457

[15] Dimitrovová, K., Costa, C., Santana, P. and Perelman, J. (2017) Evolution and Financial Cost of Socioeconomic Inequalities in Ambulatory Care Sensitive Conditions: An Ecological Study for Portugal, 2000-2014. International Journal for Equity in Health, 16, 145. https://doi.org/10.1186/s12939-017-0642-7

[16] Agrawal, V., Jaar, B.G., Frisby, X.Y., et al. (2012) Access to Health Care among Adults Evaluated for CKD: Findings from the Kidney Early Evaluation Program (KEEP). American Journal of Kidney Diseases, 59, S5-S15. https://doi.org/10.1053/j.ajkd.2011.10.043

[17] Diamantidis, C.J., Davenport, C.A., Lunyera, J., et al. (2019) Low Use of Routine Medical Care among African Americans with High CKD Risk: The Jackson Heart Study. BMC Nephrology, 20, 11. https://doi.org/10.1186/s12882-018-1190-0

[18] Hossain, W.A., Ehtesham, M.W., Salzman, G.A., et al. (2013) Healthcare Access and Disparities in Chronic Medical Conditions in Urban Populations. The Southern Medical Journal, 106, 246-254.

[19] Comino, E.J., Davies, G.P., Krastev, Y., et al. (2012) A Systematic Review of Interventions to Enhance Access to Best Practice Primary Health Care for Chronic Disease Management, Prevention and Episodic Care. BMC Health Services Research, 12, 415. https://doi.org/10.1186/1472-6963-12-415

[20] Vuik, S.I., Fontana, G., Mayer, E. and Darzi, A. (2017) Do Hospitalisations for Ambulatory Care Sensitive Conditions Reflect Low Access to Primary Care? An Observational Cohort Study of Primary Care Usage Prior to Hospitalization. BMJ Open, 7, e015704. https://doi.org/10.1136/bmjopen-2016-015704

[21] Dechambenoit, G. (2016) Access to Health Care in Sub-Saharan Africa. Surgical Neurology International, 7, 108. https://doi.org/10.4103/2152-7806.196631

[22] Ladino, M.A., Wiley, J., Schulman, I.H., et al. (2016) Tele-Nephrology: A Feasible Way to Improve Access to Care for Patients with Kidney Disease Who Reside in Underserved Areas. Telemedicine and e-Health, 22, 650-654.

https://doi.org/10.1089/tmj.2015.0197 